Brit. J. industr. Med., 1949, 6, 254.

\title{
PHOTOELECTRIC MEASUREMENT OF COAL DUST STAINS ON FILTER PAPER
}

\author{
BY \\ C. N. DAVIES and MARY AYLWARD \\ From the Medical Research Council, London School of Hygiene and Tropical Medicine
}

(RECEIVED FOR PUBLICATION MAY 18, 1949)

\section{Introduction}

Owing to the rapidity with which observations can be made, assessment of airborne dust by aspiration through filter paper, followed by photoelectric measurement of the resulting stain, has been very popular. The following account of experiments with coal dust shows how the calibration depends on particle size, and the low sensitivity of the method for small particles, when large ones are also present, is exposed. The work was carried out with the hand-pump and densitometer developed by the Pneumoconiosis Research Unit of the Medical Research Council, which has been described by Watson (1948) and by Watson and Hounam (1948). The increase in resistance to air flow through the filter paper, due to deposition of coal dust, was also studied.

\section{Experimental Method}

The coal used was dry duff, the fines from screening anthracite, which yielded 18 per cent. ash and is representative of general air dust. It was ball-milled dry, using one-inch pebbles for twenty hours, and sieved down to 200 mesh.

A known weight of dust was passed into a chamber of 189 litres, through an elutriator, under carefully controlled conditions which kept the aggregation of particles down to a minimum. During dispersal and sampling the dust cloud was fanned with a thin sheet metal propeller of low pitch, nine inches in diameter and rotating once a second.

The particle size was controlled by varying the flow through the elutriator during dispersal and by varying the interval between the termination of dispersal and the commencement of sampling from one minute to sixty minutes. During this time the cloud was not fanned.

The density of the airborne particles ranged from about $1.4 \mathrm{~g} / \mathrm{cm}^{3}$ in the case of the smaller units up to about 0.4 for the larger aggregates (Davies, 1947).

Sampling was carried out in comparison with absolute samples taken with the sedimentation cells described elsewhere (Davies, 1946). In the case of the finest cloud these had been shown to collect, over all sizes
15 per cent. more particles than the thermal precipitator. The diameter is that of a circle equal to the projected area of a particle as seen under the microscope.

The apparatus was arranged in the chamber before dispersing the dust. At the appropriate time a sedimentation sample was taken; then the hand pump was operated for the requisite number of strokes; and, finally, a second sedimentation sample was withdrawn. The average of the sedimentation counts was used to establish the dust concentration and size distribution.

A series of experiments was performed within which the cloud was reproduced as exactly as possible. The number of strokes of the hand pump differed, however, so that the amount of dust deposited on the filter paper was variable. The number of dust particles per $\mathrm{cm}^{3}$ being $\mathrm{N}$ and the number of pump strokes $\mathrm{n}$, the product Nn measures the quantity of dust which should be caught on the filter paper. Watson has shown that a linear relationship exists between $\mathrm{Nn}$ and $100 \mathrm{D}^{1.5}$, where $\mathrm{D}$ is the optical density of the coal dust deposited on the paper. The galvanometer in the P.R.U. densitometer, in addition to reading microamperes, is scaled to read $100 \mathrm{D}^{1,5}$, starting at zero for full scale deflection (50 microamps.) and reading infinity for zero current. The maximum reading which can accurately be made is 100 . The scale is graduated on the assumption that the deflection is proportional to light intensity. Hence, if $i$ is the current in microamperes, $I$ the intensity of transmitted light incident upon the photocell, and $I_{0}$ the original intensity, we have $D=\log _{10}\left(I_{0} / I\right)$ and $I_{0} / I$ $=50 / \mathrm{i}$.

Putting $R=100 \mathrm{D}^{1.5}=$ galvanometer reading when $\mathbf{R}=\mathbf{0}$ for clean filter paper, it was confirmed that

$$
\mathrm{Nn}=\mathrm{c} \mathbf{R}
$$

for a given cloud, but $\mathrm{c}$ is a function of particle size which increases for finer particles.

It was found, in addition, that a linear relationship existed for a given cloud between $\mathrm{Nn}$ and $\mathbf{P}$, the increment in pressure drop, due to coal dust, when measured across the filter paper with an air flow of one litre per minute. Hence,

$$
\mathrm{Nn}=\mathrm{c}^{\prime} \mathbf{P}
$$

The pressure is proportional to the air flow over a considerable range within which the above figure falls. 
A preliminary determination of the variability of clean filter paper (Whatman No. 1) was made. The densitometer was set to give a low reading with clean paper, so that all samples would give values of $\mathbf{R}$ falling on the scale. Forty pieces of paper gave a mean value $\mathbf{R}=1.09$ and a standard error of 0.31 . The same pieces had a mean pressure drop $P$ at one litre $/ \mathrm{min}$. of $3.51 \mathrm{~cm}$. mercury and a standard error equal to $0 \cdot 17$.

It was clear from these findings that the variation of the filter paper was so great that it was desirable to set the densitometer to read zero with the actual paper used in an experiment, except when the deposit was dense, and also to determine the pressure drop across each clean paper individually.

In a given series of experiments, that is to say with nearly constant cloud, the values of $c$ and $c^{\prime}$ in equations (1) and (2) were determined by the method of least squares supposing that no error existed in $\mathrm{Nn}$. From the different series, and by combining the results as explained below, the dependence of $c$ and $c^{\prime}$ on particle size was made evident.

\section{The Coal Dust Clouds}

Four series of experiments, $A$ to $D$, were done with clouds of increasing fineness. The same weight of coal dust was dispersed in every experiment, but the finer clouds had lost more.particles by settlement, either inside the elutriator or during the interval between dispersal and sampling. We can consider cloud $\mathrm{A}$ as basic and regard the others as modifications due to the removal of increasing proportions of the coarse end of the size distribution.

Let us take, for example, the coarsest cloud, A, and the finer cloud, B. The letters will serve as suffixes to identify measurements relating to each cloud. We want to deduce the value of the constant $\mathrm{c}_{\mathrm{A}-\mathrm{B}}$ (equation 1) for the theoretical difference cloud which contains only the coarse particles of A. It consists of the particles which settled from $A$ leaving $B$ behind. $c_{A}$ and $c_{B}$ are known from the experimental work on $A$ and $B$.

Following a discussion by Walton (1947), work by Vouk (1948) in this laboratory has shown that light screening by coal dust particles greater than one micron is nearly proportional to their total projected area of cross section, that is to the product of the mean of the squares of the diameters with $\mathrm{Nn}$, provided that the angle of acceptance of the photocell which measures light intensity is great enough to collect all the light diffracted by the particles. This is approximately the case in the P.R.U. densitometer.

However, light absorption by particles on filter paper is proportional to their total area only when the number in the deposit is small. At higher optical densities less light is cut off than would be expected on this basis because the particles overlap and the screening area is diminished. Armitage (1949) has shown that the frequency of occurrence of clumps can be expressed quite well as a function of the number of particles per unit area and the mean of the squares of their diameters, $\overline{\mathrm{d}^{2}}$. Correction terms which involve higher moments of the distribution of sizes are small, and the result is probably not very sensitive to particle shape. Also, the mean area of overlap in all possible arrangements of particles in a clump is a function of $\overline{\mathrm{d}^{2}}$.

Hence, it is evident that the light-screening effect, $\mathrm{R}$, must be expressible in terms of $\mathrm{Nn}$ and $\overline{\mathrm{d}^{2}}$, providing the particle shape does not depend too much upon size.

The constant $c$ of equation (1) must therefore be a unique function of the mean of the squares of the diameters. We can therefore write :

$$
\begin{aligned}
& \mathbf{R}_{\mathbf{A}}=(\mathrm{Nn})_{\mathbf{A}} \mathbf{f}\left(\overline{\mathrm{d}_{\mathbf{A}}^{2}}\right)=(\mathrm{Nn})_{\mathbf{A}}\left(\alpha+\beta \overline{\mathrm{d}_{\mathbf{A}}^{2}}+\ldots\right) \\
& \mathbf{R}_{\mathbf{B}}=(\mathrm{Nn})_{\mathbf{B}} \mathrm{f}\left(\overline{\mathrm{d}_{\mathbf{B}}^{2}}\right)=(\mathrm{Nn})_{\mathbf{B}}\left(\alpha+\beta \overline{\mathrm{d}_{\mathbf{B}}^{2}}+\ldots\right)
\end{aligned}
$$

If the same number of pump strokes were made in sampling clouds A and B, then, for the theoretical difference cloud,

$$
(\mathrm{Nn})_{\mathbf{A}-\mathbf{B}}=(\mathrm{Nn})_{\mathbf{A}}-(\mathrm{Nn})_{\mathbf{B}}
$$

so that

$\mathbf{R}_{\mathbf{A}-\mathbf{B}}=\left\{(\mathrm{Nn})_{\mathbf{A}}-(\mathrm{Nn})_{\mathbf{B}}\right\} \mathbf{f}\left\{\frac{(\mathrm{Nn})_{\mathbf{A}} \overline{\mathrm{d}_{\mathbf{A}}^{2}}-(\mathrm{Nn})_{\mathbf{B}} \overline{\mathrm{d}_{B}^{2}}}{(\mathrm{Nn})_{\mathbf{A}}-(\mathrm{Nn})_{\mathbf{B}}}\right\}$

If the function $f$ is taken as linear over the limited range between $\overline{\mathrm{d}_{\mathrm{A}}^{2}-\mathrm{B}}$ and $\overline{\mathrm{d}_{\mathrm{B}}}$ it is easy to see by expanding the last expression that

$$
\mathbf{R}_{\mathbf{A}-\mathbf{B}}=\mathbf{R}_{\mathbf{A}}-\mathbf{R}_{\mathbf{B}}
$$

Also, from equation (1)

$$
c_{A-B} R_{A-B}=c_{A} R_{A}-c_{B} R_{B}
$$

Eliminating $\mathbf{R}_{\mathrm{A}-\mathrm{B}}$ between the last two equations gives

$$
c_{A-B}=\frac{c_{A} R_{A}-c_{B} R_{B}}{R_{A}-R_{B}}
$$

Putting $\nu=N_{A} / N_{B}=c_{A} R_{A} / c_{B} R_{B}$, this can be simplified to

$$
c_{A-B}=\frac{c_{A}(\nu-1)}{\nu-c_{\Delta} / c_{B}}
$$

A corresponding formula can be deduced for the constants, $c^{\prime}$, of equation (2), assuming that the permeability of the deposit to air flow depends on the surface area of the particles which is related to $\overline{\mathrm{d}^{2}}$. 
TABLE 1

CHARACTERISTICS OF THE DUST CLOUDS

\begin{tabular}{|c|c|c|c|c|c|c|c|c|}
\hline \multirow{2}{*}{ Cloud } & \multirow{2}{*}{$\nu$} & \multirow{2}{*}{$N$} & \multirow{2}{*}{$\begin{array}{l}\text { Standard } \\
\text { deviation } \\
\text { of } N\end{array}$} & \multicolumn{4}{|c|}{$\begin{array}{l}\text { Diameter }(\mu) \text { below which proportion of } \\
\text { particles was }\end{array}$} & \multirow{2}{*}{$\begin{array}{l}\text { Mean } d^{2} \\
\left(\text { in } \mu^{2}\right)\end{array}$} \\
\hline & & & & $20 \%$ & $50 \%$ & $80 \%$ & $95 \%$ & \\
\hline $\begin{array}{c}\text { A } \\
\text { B } \\
\mathbf{C} \\
\mathbf{D} \\
\mathbf{C}-\mathbf{D} \\
\mathbf{B}-\mathbf{D} \\
\mathbf{B}-\mathbf{C} \\
\text { A-C } \\
\mathbf{A}-\mathbf{D}\end{array}$ & $\begin{array}{l}\bar{Z} \\
\bar{Z} \\
2.70 \\
4.75 \\
1.76 \\
1.75 \\
4.73\end{array}$ & $\begin{array}{l}7,991 \\
8,021 \\
4,562 \\
1,689 \\
2,873 \\
6,332 \\
3,459 \\
3,429 \\
6,302\end{array}$ & $\begin{array}{r}9 \cdot 7 \\
5 \cdot 4 \\
11 \cdot 0 \\
15 \cdot 8 \\
= \\
= \\
=\end{array}$ & $\begin{array}{l}2 \cdot 27 \\
2 \cdot 24 \\
1.95 \\
1.38 \\
2 \cdot 78 \\
2.63 \\
2.90 \\
3.40 \\
2 \cdot 72\end{array}$ & $\begin{array}{l}3 \cdot 8 \\
3 \cdot 6 \\
3.03 \\
2 \cdot 26 \\
3.60 \\
4.02 \\
4.5 \\
5 \cdot 3 \\
4 \cdot 3\end{array}$ & $\begin{array}{l}6 \cdot 3 \\
5 \cdot 8 \\
4 \cdot 7 \\
3 \cdot 26 \\
5 \cdot 3 \\
6 \cdot 2 \\
6 \cdot 9 \\
8 \cdot 6 \\
7 \cdot 0\end{array}$ & $\begin{array}{r}10 \cdot 4 \\
8.6 \\
6.9 \\
4 \cdot 6 \\
7.5 \\
8.7 \\
9.4 \\
13.4 \\
11.0\end{array}$ & $\begin{array}{c}32 \cdot 0 \\
22 \cdot 5 \\
15 \cdot 6 \\
7 \cdot 24 \\
19 \cdot 7 \\
26 \cdot 3 \\
32 \cdot 0 \\
55 \cdot 3 \\
38 \cdot 0\end{array}$ \\
\hline
\end{tabular}

TABLE 2

SUMMARY OF MEASUREMENTS

\begin{tabular}{|c|c|c|c|c|c|c|c|c|c|}
\hline \multirow{2}{*}{ Experiment } & \multirow{2}{*}{ Cloud } & \multicolumn{3}{|c|}{ No. of particles per c.cm. } & \multicolumn{2}{|c|}{ Densitometer } & \multirow{2}{*}{$\begin{array}{c}\text { Pressure } \\
\text { difference, } \\
P \text {, in } \mathrm{cm} . \\
\mathbf{H g} .\end{array}$} & \multirow[b]{2}{*}{$n$} & \multirow[b]{2}{*}{$N n$} \\
\hline & & Cell $a$ & Cell $b$ & Mean $N$ & $\underset{\text { microamps. }}{i \text { in }}$ & $\boldsymbol{R}$ & & & \\
\hline $\begin{array}{l}\mathbf{C} \\
\mathbf{E} \\
\mathbf{F} \\
\mathbf{G}\end{array}$ & $\mathbf{A}$ & $\begin{array}{l}9,320 \\
7,312 \\
7,120 \\
9,707\end{array}$ & $\begin{array}{l}8,520 \\
7,828 \\
6,773 \\
7,433\end{array}$ & $\begin{array}{l}8,875 \\
7,570 \\
6,947 \\
8,570 \\
7,991\end{array}$ & $\begin{array}{r}19 \cdot 5 \\
15 \cdot 8 \\
5 \cdot 8 \\
3 \cdot 2\end{array}$ & $\begin{array}{r}26 \\
36 \\
90 \\
138\end{array}$ & $\begin{array}{l}1 \cdot 1 \\
2 \cdot 0 \\
2 \cdot 7 \\
4 \cdot 1\end{array}$ & $\begin{array}{r}5 \\
10 \\
20 \\
25\end{array}$ & $\begin{array}{r}44,375 \\
75,700 \\
138,940 \\
214,200\end{array}$ \\
\hline $\begin{array}{l}\mathbf{Y} \\
\mathbf{Z} \\
\mathbf{A} \\
\mathbf{B}\end{array}$ & B & $\begin{array}{l}9,070 \\
7,796 \\
7,414 \\
8,553\end{array}$ & $\begin{array}{l}8,235 \\
7,621 \\
7,652 \\
7,827\end{array}$ & $\begin{array}{l}8,652 \\
7,708 \\
7,533 \\
8,190 \\
8021\end{array}$ & $\begin{array}{r}16 \cdot 8 \\
12 \cdot 2 \\
7 \cdot 7 \\
4 \cdot 6\end{array}$ & $\begin{array}{r}33 \\
48 \\
75 \\
109\end{array}$ & $\begin{array}{l}1 \cdot 0 \\
1 \cdot 8 \\
2 \cdot 8 \\
3 \cdot 8\end{array}$ & $\begin{array}{l}10 \\
20 \\
30 \\
40\end{array}$ & $\begin{array}{r}86,520 \\
154,160 \\
225,990 \\
327,600\end{array}$ \\
\hline $\begin{array}{l}\mathbf{R} \\
\mathbf{W} \\
\mathbf{S} \\
\mathbf{X} \\
\mathbf{T} \\
\mathbf{U} \\
\mathbf{V}\end{array}$ & C & $\begin{array}{l}4,979 \\
4,837 \\
5,735 \\
3,813 \\
4,131 \\
4,603 \\
4,811\end{array}$ & $\begin{array}{l}4,819 \\
4,383 \\
4,950 \\
3,877 \\
3,915 \\
2,187 \\
3,454\end{array}$ & $\begin{array}{l}4,899 \\
4,610 \\
5,343 \\
3,845 \\
4,023 \\
3,395 \\
4,123 \\
4,562\end{array}$ & $\begin{array}{l}29 \cdot 2 \\
18 \cdot 2 \\
15 \cdot 8 \\
14 \cdot 4 \\
7 \cdot 0 \\
8 \cdot 9 \\
4 \cdot 0\end{array}$ & $\begin{array}{r}11 \\
29 \\
36 \\
40 \\
81 \\
67 \\
120\end{array}$ & $\begin{array}{l}0.7 \\
0.6 \\
1.5 \\
1.2 \\
1.4 \\
1.6 \\
2.4\end{array}$ & $\begin{array}{r}10 \\
20 \\
40 \\
40 \\
80 \\
80 \\
150\end{array}$ & $\begin{array}{r}48,990 \\
92,200 \\
213,720 \\
153,800 \\
321,840 \\
271,600 \\
619,950\end{array}$ \\
\hline $\begin{array}{l}\mathbf{I} \\
\mathbf{J} \\
\mathbf{O} \\
\mathbf{P} \\
\mathbf{L} \\
\mathbf{N} \\
\mathbf{K} \\
\mathbf{M}\end{array}$ & D & $\begin{array}{l}2,202 \\
1,426 \\
1,839 \\
1,918 \\
1,984 \\
1,993 \\
1,146 \\
1,613\end{array}$ & $\begin{array}{l}1,730 \\
1,580 \\
2,074 \\
1,331 \\
1,622 \\
1,975 \\
1,252 \\
1,336\end{array}$ & $\begin{array}{l}x, 901 \\
1,961 \\
1,503 \\
1,957 \\
1,625 \\
1,803 \\
1,984 \\
1,200 \\
1,475 \\
1,689\end{array}$ & $\begin{array}{l}42 \cdot 2 \\
26 \cdot 3 \\
23 \cdot 2 \\
23 \cdot 2 \\
18 \cdot 2 \\
15 \cdot 2 \\
10 \cdot 3 \\
10 \cdot 3\end{array}$ & $\begin{array}{l}2 \\
14 \cdot 2 \\
19 \\
19 \\
-29 \\
38 \\
56 \\
56\end{array}$ & $\begin{array}{l}0 \cdot 1 \\
0 \cdot 3 \\
0 \cdot 4 \\
0 \cdot 5 \\
0 \cdot 8 \\
0 \cdot 9 \\
1 \cdot 1 \\
1 \cdot 1\end{array}$ & $\begin{array}{r}10 \\
60 \\
100 \\
100 \\
170 \\
170 \\
300 \\
300\end{array}$ & $\begin{array}{r}19,610 \\
90,180 \\
195,700 \\
162,500 \\
306,500 \\
337,300 \\
375,600 \\
400,800\end{array}$ \\
\hline
\end{tabular}


These formulæ are useful because they enable the constants for the densitometer, or the flow resistance increase, to be derived for difference clouds obtained from any two experimental clouds and so extend the information gained from the experiments.

The characteristics of the experimental clouds, $A$ to $\mathrm{D}$, and of the calculated difference clouds are set out in Table 1. The difference in the number of particles per cm. ${ }^{3}$ in clouds A and B is smaller than the experimental error of counting, but the extra particles of $\mathbf{A}$ are all large ones and have a considerable effect upon the densitometer and pressure measurements.

\section{Experimental Results}

The experimental figures are summarized in Table 2 for the four groups $A$ to $D$ through each of which, as nearly as possible, similar clouds were dispersed.

The quantities $c$ in equation (1) and $c^{\prime}$ in equation (2) were computed by least squares from the values of $\mathbf{N}, \mathbf{n}, \mathbf{R}$, and $\mathbf{P}$ given in Table 2. They are shown in Table 3 together with the values for the difference clouds which were computed by means of equation (3). The values of $c$ and $c^{\prime}$ relate, therefore, to clouds having different size distributions given in Table 1.

By substituting $c$ and $c^{\prime}$ into equations (1) and (2) the deviations between the observations, $y_{i}^{\prime}$, and the

TABLE 3

CONSTANTS OF EQUATIONS (1) AND (2), CALCULATED BY LEAST SQUARES FROM THE EXPERIMENTAL DATA AND BY EQUATION (3) FOR THE DIFFERENCE CLOUDS .

\begin{tabular}{|c|c|c|c|c|}
\hline \multirow[b]{2}{*}{ Cloud } & \multicolumn{2}{|c|}{ Equation (1) } & \multicolumn{2}{|c|}{ Equation (2) } \\
\hline & $c$ & $\begin{array}{c}\text { Standard } \\
\text { error of } \\
\text { experimental } \\
\text { values of } R \\
\text { from } \\
\text { calculated } \\
\text { values, } \\
\%\end{array}$ & $c^{\prime}$ & $\begin{array}{c}\text { Standard } \\
\text { error of } \\
\text { experimental } \\
\text { values of } P \\
\text { from } \\
\text { calculated } \\
\text { values, } \\
\%\end{array}$ \\
\hline $\begin{array}{c}\text { A } \\
\text { B } \\
\text { C } \\
\text { D } \\
\text { C-D } \\
\text { B-D } \\
\text { B-C } \\
\text { A-C } \\
\text { A-D }\end{array}$ & $\begin{array}{r}1,584 \\
2,970 \\
4,970 \\
9,010 \\
3,930 \\
2,520 \\
1,950 \\
800 \\
1,300\end{array}$ & $\begin{array}{l}18 \\
10 \\
17 \\
25 \\
- \\
- \\
- \\
-\end{array}$ & $\begin{array}{r}50,100 \\
83,500 \\
227,000 \\
424,000 \\
179,000 \\
68,800 \\
45,700 \\
24,600 \\
40,600\end{array}$ & $\begin{array}{r}31 \\
4 \\
93 \\
44 \\
- \\
- \\
- \\
-\end{array}$ \\
\hline
\end{tabular}

calculated values, $y_{i}$, were found. These were expressed as percentages of the calculated values and the standard errors,

$$
100 \sqrt{\frac{\sum_{i}\left[\left(y_{i}^{\prime}-y_{i}\right) / y_{i}\right]^{2}}{\text { No. of observations }-2}},
$$

of the experimental results for $\mathbf{R}$ and $\mathbf{P}$ were worked out. These are also given in Table 3 . It will be noticed that the observations are more consistent for the coarser clouds. In fact the pressure readings show so great a scatter as to make this method hardly worth using for fine dust.

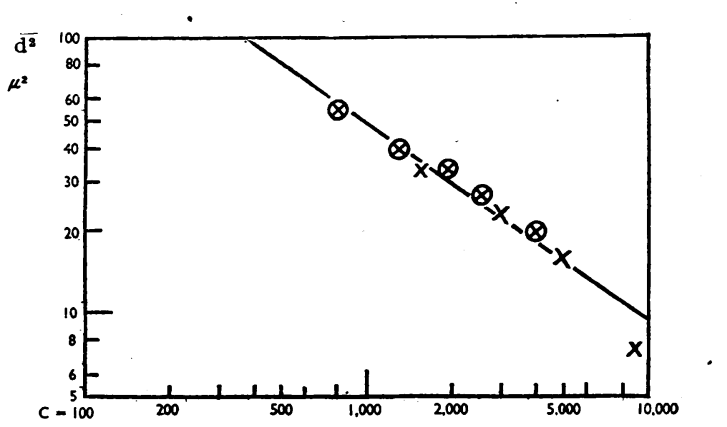

Figure.-The relationship between $c$ (equation 1) and the mean of the squares of the particle diameters.

$\times \quad$ Experimental clouds $A-D$.

$\oplus \quad$ Difference clouds calculated by equation 4 . Equation 4.

It is clear at once that there is only a small correlation between the constants, $c$ or $c^{\prime}$, and the 20 per cent. or 50 per cent. level of the distribution of diameter (Table 1). However, the larger diameters are closely dependent on $c$ and $c^{\prime}$.

We see, therefore, that $c$ and $c^{\prime}$ depend on the coarse end of the particle size distribution and are not so much upon the finer particles.

The distributions of the squares of the particle diameters have also been calculated and the means of the squares have been tabulated for each cloud. The mean is equal to $\Sigma f_{i} d_{i}^{2}$, where $f_{i}$ is the proportion or frequency of particles in a small range of sizes centred on $d_{i}$ and the sums are taken over all sizes present.

If the particles are geometrically similar these distributions relate to the surface area of the particles. In fact, the larger sizes, which include some aggregates, have a greater ratio of surface to mass than the small.

The figure shows the relationship between the constant, $c$, and the mean of the squares of the diameters. Points for experimental clouds and those calculated for difference clouds fall on a common 
curve thus justifying the method used to calculate $\mathrm{c}_{\mathrm{A}-\mathrm{B}}$. The line plotted is the equation

$$
c=234,000\left(\bar{d}^{2}\right)-1 \cdot 4
$$

All points lie close to this except the one for the finest experimental cloud. Perhaps this is because fine particles are more compact in shape than coarse ones.

The constant of equation (2) for the pressure drop is given by

$$
c^{\prime}=6,680,000\left({\overline{d^{2}}}^{-1 \cdot 4}\right.
$$

\section{Discussion}

Combining the experimental results leads to the following empirical equation

$$
R=100 D^{1 \cdot 5}=\frac{\mathrm{Nn}\left(\overline{\mathrm{d}^{2}}\right)}{234,000}
$$

- This can be used to determine the mean square particle diameter of coal dust if the number concentration, $\mathbf{N}$, is known. Since $\mathrm{N}$ is little influenced by a relatively small proportion of coarse particles it can be estimated with the thermal precipitator. For the same reason a sufficiently reliable value for the most probable diameter, $d_{p}$, can also be obtained from thermal precipitator counts. From these two quantities, $d_{p}$ and $\vec{d}^{2}$, it is possible to construct the entire distribution law if it is of the two-constant type.

For example, coal dust often follows the lognormal distribution,

$$
\frac{\mathrm{dN}}{\mathrm{d}(\operatorname{lnd})}=\frac{100}{\sqrt{2 \pi} \ln \sigma_{\mathrm{g}}} \exp \left\{-\frac{1}{2}\left[\frac{\ln \left(\mathrm{d} / \mathrm{d}_{\mathrm{m}}\right)}{\ln \sigma \mathrm{g}}\right]^{2}\right\}
$$

where $d_{m}$ is the median diameter and $1 n \sigma_{g}$ is the standard deviation of the logarithms of the diameters. In signifies the natural logarithm.

In this case the median can be found from the experimental observations using

$$
d_{m}^{4}=\overline{d^{2}} \cdot d_{p}^{2}
$$

and the other constant from

$$
\left(\ln \sigma_{g}\right)^{2}=\ln \left(d_{m} / d_{p}\right)
$$

These expressions were deduced from equation (7).

It is thus possible to use the thermal precipitator, which is not satisfactory for coarse dust, in conjunction with the P.R.U. hand-pump outfit, which - is insensitive to fine dust, as a means of obtaining the complete size distribution of airborne coal dust.

The pressure difference method of assessing deposits on filter paper is not, at present, recommended.

\section{Summary}

Airborne dust is frequently assessed by aspiration through a filter paper followed by photoelectric measurement of the resulting stain. This account of experiments with coal dust shows how the calibration depends on particle size, and the low sensitivity of the method for small particles, when large ones are also present, is exposed. The work was carried out with a hand-pump and densitometer developed by the Pneumoconiosis Research Unit of the Medical Research Council. The theoretical basis of the measurement is discussed. The increase in resistance to air flow through the filter paper, due to the deposition of coal dust, was also studied.

The authors are grateful to Mr. P. Armitage for his careful criticism of this paper, and to Dr. T. Bedford for his interest and encouragement while the work was in progress.

\section{REFERENCES}

Armitage, P. (1949). Biometrika (in the press).

Davies, C. N. (1946). Proc. Roy. Soc. B., 133, 286.

- (1947). Symposium on particle size analysis. Inst. Chem. Eng. and Soc. Chem. Ind., In the press

Vouk, V. (1948). "Scattering and extinction of light by dust particles." Ph.D. Thesis, London : 1948.

Walton, W. H. (1947). Symposium on particle size analysis. Inst. Chem. Eng. and Soc. Chem. Ind., In the press.

Watson W. H. (1948). Brit. J, indust. Med., 5, 198

- and Hounam, R. F. (1948). Coll. Guardian, 176, 447. 